\section{Follow-up results of a pure retroperitoneoscopic/extraperi toneal nephroureterectomy for upper tract urothelial tumors}

\author{
Wael Y. Khoder, Stefan Tritschler, \\ Nicolas Haseke, Patrick J. Bastian, \\ Christian G. Stief, Armin J. Becker \\ Department of Urology, University \\ Hospital Munich-Grosshadern, \\ Ludwig-Maximilians-University Munich, \\ Munich, Germany
}

\section{Abstract}

We present the results of a pure retroperitoneoscopic/extraperitoneal nephroureterectomy (RENU) for upper urinary tract transitional cell cancer (UT-TCC). After establishment of RENU in benign indications ( $\mathrm{n}=21$ Patients), 14 patients (age range 51-92 years, mean 71.6) with UT-TCC have undergone the technique in our clinic from October 2005 to October 2008. This paper reports the operative procedure, clinical results and follow up. Total operative time was 110-240 minutes (median 154.5). Average blood loss was $132 \mathrm{~mL}$. Tumor localization in oncology patients was renal pelvis (63.6\%), ureter (18.2\%) or both (18.2\%). Postoperative tumor stages were Ta $(\mathrm{n}=2)$, Tis $(\mathrm{n}=2), \mathrm{T} 1(\mathrm{n}=3), \mathrm{T} 2(\mathrm{n}=3)$ and T3 $(\mathrm{n}=4)$ without lymph node involvement. No perioperative complications were observed. Urethral catheters were removed on Day 6-8 post surgery (median Day 7). Recovery to normal life activity ranged from 8 to 30 days (mean 17.8). During the 4-36 month (median 23) follow-up period, there was one mortality due to cancer progression. Four patients had developed superficial bladder cancer disease requiring regular cystoscopic resections. One patient had coincidental Bellini duct renal tumor and developed psoas metastasis after eight months. The 2-year tumor specific survival rate is $91 \%$. The retroperitoneoscopic/ extraperitoneal nephroureterectomy is a lowrisk and minimally invasive procedure to be used whenever nephroureterectomy is indicated. It is an attractive alternative to both laparoscopic and open techniques and adheres to the oncological principles of radical nephroureterectomy. Short-term follow-up data showed no increased risk of tumor recurrence. However, long-term results are needed before this technique can be established as standard UT-TCC therapy.

\section{Introduction}

The standard treatment for transitional cell carcinoma (TCC) of the upper urinary tract is nephroureterectomy with excision of a bladder cuff. ${ }^{1}$ Based on the first report by McDonald in 1952 , several authors tried to minimize the access trauma by use of laparoscopic nephroureterectomy which was associated with less morbidity and produced long-term results comparable to those of open surgery. ${ }^{2-7}$

The indication for laparoscopic nephroureterectomy (LNU) in upper tract TCC has not yet been well defined, although most authors still recommend that high stage and high grade tumors should be a contraindication, ${ }^{24,6}$ Recently, Muntener et al. reported good oncological outcome after LNU with a median follow-up time of 74 months and supported the use of LNU as the standard of care for high grade or high stage upper tract TCC. ${ }^{8}$

The removal of the distal part of the ureter with a bladder cuff may be performed by an endoscopic transurethral detachment technique, laparoscopic dissection of the distal ureter with extravesical stapling of the bladder wall, the transurethral circumcision of the orifice and antegrade stripping (i.e. pluck-off technique), and the transvesical endoscopic detachment of the ureter (i.e. Cleveland technique). , $, 4,7,9-11^{2}$

We have been applying a pure retroperitoneoscopic/extraperitoneal nephroureterectomy (RENU) procedure for TCC of the upper urinary tract upper urinary tract transitional cell cancer (UT-TCC) since October 2005 to minimize surgical morbidity. Evaluation of the efficacy of this technique, the operative procedure, clinical results and follow-up data are presented.

\section{Materials and Methods}

After establishment of RENU in benign indications ( $\mathrm{n}=21$ Patients), the technique was used in 14 patients (age range 51-92 years, mean 71.6) with UT-TCC in our clinic from October 2005 till October 2008. There were 8 men and 6 women with TCC of the renal pelvis and/or ureter. Three patients had undergone previous open abdominal procedures in the form of one appendecectomy and 2 transperitoneal hysterectomies. The open part of the procedure was not always necessary for the benign indications; these were symptomatic non-functioning kidneys due to high grade reflux $(n=5)$ or obstructive lower ureter $(n=16)$.

After the induction of general anesthesia, the patient was placed in a lateral position with the pelvis in an oblique position $\left(70^{\circ}\right)$ (Figure 1).
Correspondence: W. Khoder, Urologische Klinik und Poliklinik, Klinikum Grosshadern, Marchioninistr. 15, 81377, Muenchen, Germany. Tel. +89.7095.0 Ext - Fax: +089.7095.4740.

E-mail: wael.khoder@med.uni-muenchen.de

Key words: retroperitoneoscopic nephroureterectomy, nephrourereterectomy, upper urinary tract, urothelial tumor

Received for publication: 17 June 2011.

Revision received: 17 June 2011.

Accepted for publication: 21 October 2011.

This work is licensed under a Creative Commons Attribution NonCommercial 3.0 License (CC BYNC 3.0).

CC Copyright W.Y. Khoder et al., 2011

Licensee PAGEPress, Italy

Surgical Techniques Development 2011; 1:e33 doi:10.4081/std.2011.e33

A $1 \mathrm{~cm}$ incision was made at the tip of the last rib along the mid-axillary line. The external, internal oblique and transversus abdominus muscle fibers were bluntly separated with a Kocher clamp. A balloon made from the middle finger of a size 8 surgical glove and tied to the top of a $12 \mathrm{~mm}$ trocar was then placed in the retroperitoneal space and inflated with 500-700 mL of saline to produce a working space. Inflation was maintained for a couple of minutes to allow hemostasis. The balloon was removed and the trocar was fixed in place using 0 -nylon suture to prevent carbon dioxide leakage (port A). Carbon dioxide insufflation at a pressure of $13 \mathrm{mmHg}$ was started to maintain the working space and diagnostic retroperitoneoscopy using a $30^{\circ}$ optic was performed. The peritoneum was dissected from the anterior abdominal wall using the optic to insert another port (12 $\mathrm{mm}$ for the right side or $5 \mathrm{~mm}$ for the left side nephroureterectomy) in the anterior axillary line 2-3 cm above and medial to the anterior superior iliac spine (port B). The second working port was made 1 $\mathrm{cm}$ from the middle point of the line between both ports (port $\mathrm{C}$ ). The whole procedure was carried out through both these ports.

Retroperitoneoscopic dissection of the kidney is performed in an en bloc fashion, together with some perirenal fat, as described in literature $^{4,5}$ (Figure 2).

The ureter was then dissected downwards up to the bladder. This requires the surgeon and assistant to slightly modify their positions to look toward the patients' pelvis. After dissection of the ureter, lymphadenectomy was performed and lymph nodes were put in a bag to be removed through the incision later on. After ensuring adequate hemostasis and that laparoscopy was no longer required, the table 
is slightly tilted toward the surgeon for the open part of the procedure to be performed. A small incision (average $7 \mathrm{~cm}$ ) was made as an elongation to port $\mathrm{B}$ to bring out the kidney and place it at the patient's pelvis from outside (Figure 3A). The dissection of the ureter is completed distally up to the bladder wall (Figure 3B and C). At the vesicoureteral junction, the detrusor muscle was incised along the ureter in three directions while retracting the ureter proximally, thus obtaining a $2.5 \mathrm{~cm}$ high tent-shaped bladder cuff, including the intramural ureter, ureteral orifice, and vesical mucosa (Figure 3D).

A traction suture was made at its upper limit and the ureter was closed using a laparoscopic hemolock clip. The distal ureter with a $2.5 \mathrm{~cm}$ diameter bladder cuff was then progressively cut under vision with simultaneous suturing of the bladder wall. The specimen was removed intact and the bladder was completely sutured in two layers using 3-0 Vicryl sutures. The bladder was filled with saline to ensure dryness. Adrenalectomy was not necessary in any patient. Drainage tubes were placed inside the $5 \mathrm{~mm}$ trocar (port $\mathrm{C}$ or $\mathrm{B}$ ) in the renal bed passing through the perivesical space. The rest incisions were closed at the end of the procedure (Figure 4).

The drainage tube was usually removed on Day 3 post surgery and cystography was performed on Day 7 before removing the urethral catheter. All patients were followed up according to guidelines with cystoscopy, urine cytology every $3-6$ months, and computed tomography every six months.

\section{Results}

The perioperative findings are shown in Tables 1 and 2 .

The operative time was 110-240 minutes (median 154.5) including the time required to resect the bladder cuff which was 20-50 min. The estimated blood loss was 50-400 ml (average 132). Median Body Mass Index was 26 $\mathrm{kg} / \mathrm{m}^{2}$. Time to the first oral food intake was 8$12 \mathrm{~h}$. No postoperative complications or urine leakage were observed in any of the patients. A continuous epidural analgesia was given during the initial three postoperative days; this is standard care in our clinic. Metamezole was then used when needed. The urethral catheters were removed Day 6-8 post surgery (mean Day 7). The time to recovery to normal life activity ranged from 8-30 days (mean 17.8). No patient had lymph node disease. The number of extracted lymph nodes ranged from 2 to 6 (mean 3).

Follow up was 4-36 months (median 23). One female patient had disease progression with metastasis and died from her tumor after eight months. Four patients have pT3, R0 tumor and have had no metastasis up till now. Four patients (28.6\%) had developed superficial bladder cancer disease that was successfully controlled with regular cystoscopic resections. Cystoscopy in these patients assured complete removal of the ureteral end with a completely absent ipsilateral ureteric ostium. No patient experienced problems related to the operation during the entire follow-up period.

\section{Discussion}

The standard treatment for localized TCC of the renal pelvis and ureter is radical nephroureterectomy, which includes resection of the kidney and ureter with a bladder cuff. ${ }^{1}$ Laparoscopic nephroureterectomy was developed to reduce the morbidity associated with this approach. Indeed, several investigators have recently suggested its benefits in terms of patient recovery with disease control comparable to that of traditional open surgery. ${ }^{2-8,10-11}$ Laparoscopic nephroureterectomy can be performed via a transperitoneal or retroperitoneal access. The advantage of the retroperitoneal approach is partly the avoidance of intraabdominal Organ injuries and tumor spillage into the intra-abdominal cavity.

We adopted RENU as a modification of the already very good technique of retroperitoneo-
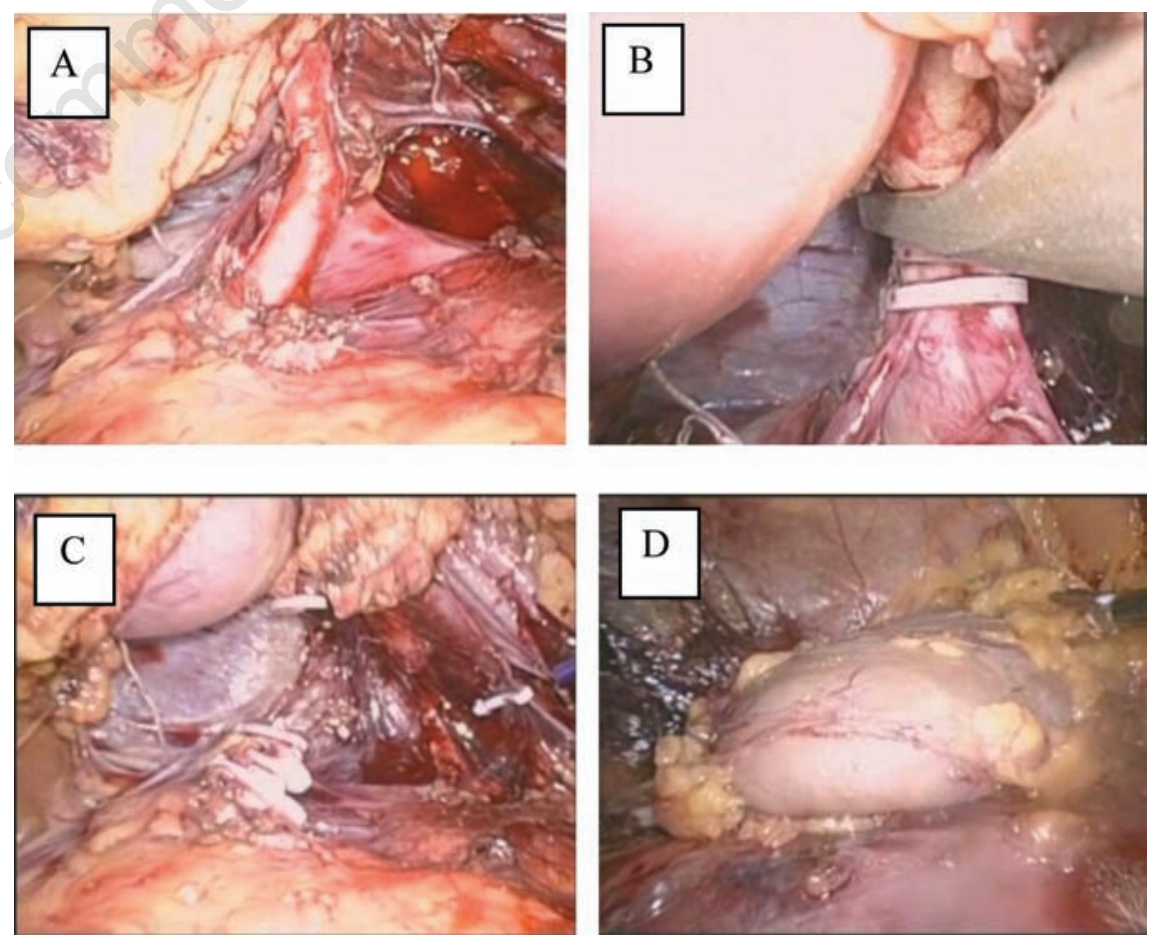

Figure 2. Retroperitoneoscopic right nephrectomy. (A) Dissection of renal vessels. (B) The renal artery and vein are individually controlled with hemolock clips. (C) Cutting the vessels and dissection of the kidney. (D) The renal specimen circumferentially mobilized retroperitoneoscopically external to Gerota's fascia. scopic nephrectomy established in our department. The patients with benign indications were needed to establish the technique. The open part of the procedure was not necessary in this setting but extraperitoneal laparoscopic bladder cuff excision was not a safe approach to be used for malignant indications. Another ventral trocar was needed with removal of the specimen through a similar incision. This led us to perform this part of the intervention as an open surgery approach through the extraction incision for UT-TCC indications. All patients reported uneventful follow up with disappearance of the symptoms presented (e.g. chronic pain, recurrent infections) which also confirmed the benefits of RENU for this indi-

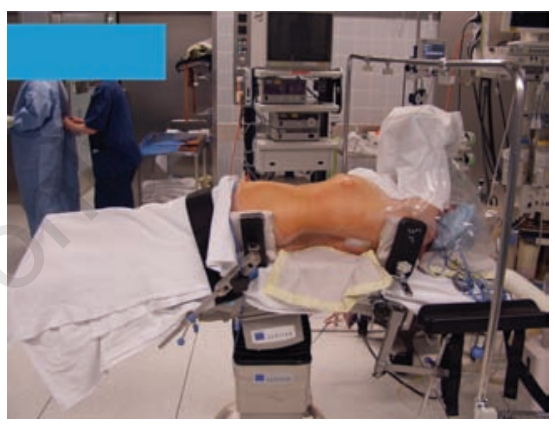

Figure 1. Patient position for the procedure; slightly tilted in a lateral position with the pelvis in an oblique position $\left(70^{\circ}\right)$. 
cation.

This technique differs from others described in literature in that the position of the patient allows both parts of the procedure to be completed in a reasonably short time without needing to changing patient position and without causing any additional technical difficulties. Also the use of only two working trocars and a small incision as an extension of the already present medial one, away from the flank region, resulted in minimal scaring. Lastly, the extraperitoneal resection of the distal ureter with a bladder cuff was completely performed with an open surgical approach.

This technique compromises the known advantages mentioned in literature that an extraperitoneal approach to the kidneys avoids the risk of intra-abdominal urinary leakage and allows for intact specimen removal, therefore minimizing the incidence of local recurrence. ${ }^{12}$ In the current series, no patient had local recurrence in the operative field. There were no complications regarding intra-abdominal injury. This confirms the benefit of this complete retroperitoneal/extraperitoneal approach.

The avoidance of a flank incision and the use of only 3 trocars minimizes scaring and gives better cosmetic results. This also has only a slight effect on subsequent body configuration, as stated by Yoshimura et al. ${ }^{13}$

The technique of ureterectomy and bladder cuff excision has not yet been standardized. A number of minimal invasive approaches to the distal ureter have been reported. ${ }^{2-8}$ However, the endoscopic techniques have a greater risk of local recurrence and stone formation in the staple lines. ${ }^{14}$ Our exclusively extraperitoneal approach provides a greater safety margin to this part of the procedure

Moreover, various authors have described different alternative methods to open dissection of the lower ureter so as to avoid exposing the urothelium, for example, after repositioning the patient through a Para rectal incision ${ }^{15}$ or a hand-assisted technique. ${ }^{16,17}$ One advantage of the described RENU-technique is that the complete removal of the bladder cuff, including the ureteral orifice and vesical mucosa, could be confirmed visually during surgery. This was proved by postoperative cystoscopy which confirmed the complete absence of ipsilateral ostium. However, the biggest advantage is offered by the complete extraperitoneal excision.

Furthermore, the median of our muscle splitting incisions was $7 \mathrm{~cm}$ which is shorter than that used in the muscle cutting approach of open surgery and even the recently published laparoscopic series. We believe that the open part of the procedure does not adversely affect patient recovery compared with the complete retroperitoneoscopic and laparoscopic approaches. Analgesic requirements were also comparable with the published data. The short-
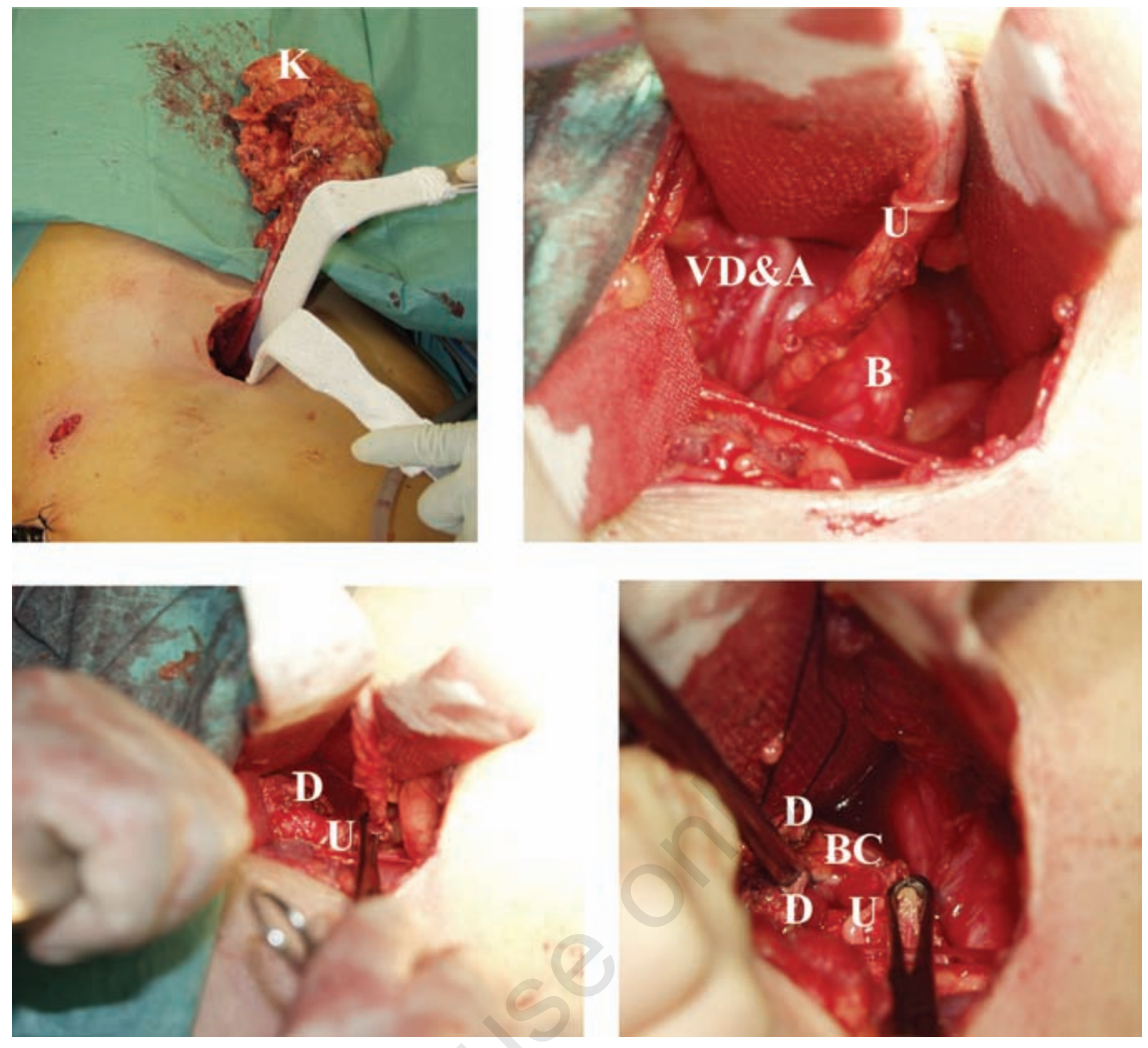

Figure 3. The different steps of left ureterectomy with bladder cuff excision in a male patient. (A) External view showing the kidney placed over the patient's pelvis from outside and the groin incision. (B) Ureter dissected extraperitoneally at the pelvic entry showing the related structures (vas deferens and its artery and urinary bladder). (C) The pre-vesical left ureter after the exposure of the detrusor muscle. (D) Tenting of the bladder mucosa after dividing the detrusor in 3 directions. The first suture is inserted.

Note that the ureter is retracted using fine traction with an Allis clamp.

K: kidney; VD\&A: vas deferens and its artery; U: ureter; B: urinary bladder; D: detrusor muscle; BC: tented urinary bladder cuff.
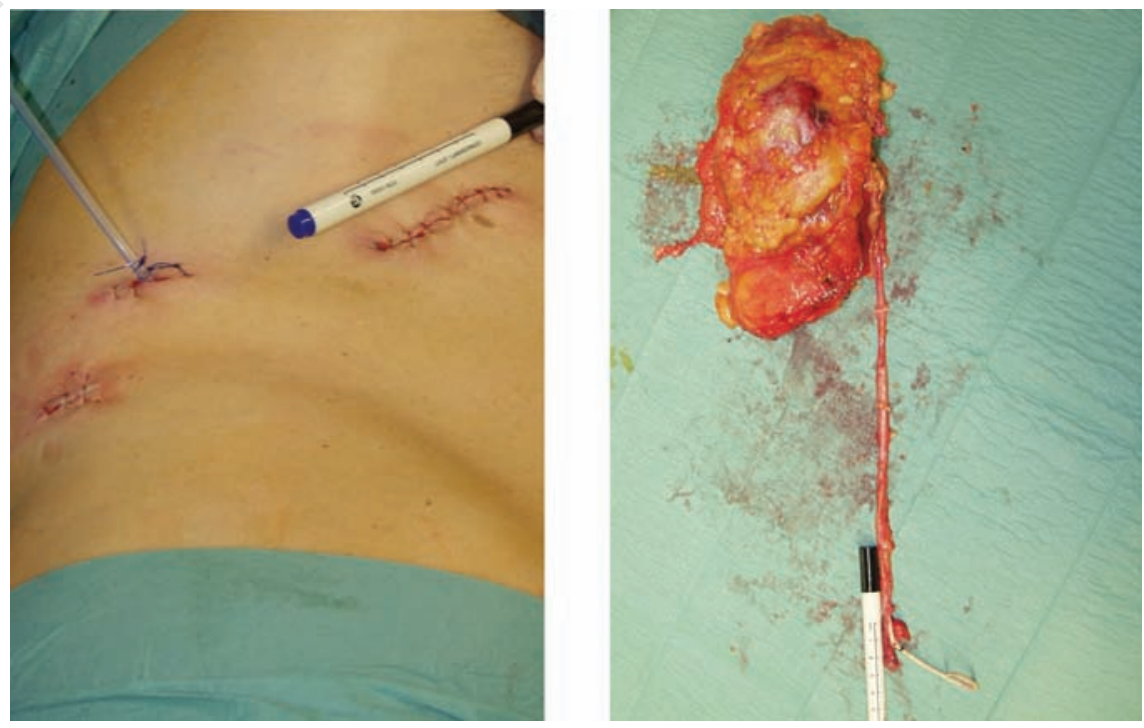

Figure 4. Operative scars after left retroperitoneoscopic/extraperitoneal nephroureterectomy (RENU) in a male patient. 
er operative time and low blood loss may be in part due to our experience with the retroperitoneoscopic procedures. In addition, the mean operative time, time to oral diet, urethral catheter time, and length of hospital stay were also comparable with literature. A comparison between the available published series is shown in Table 3.

In our series, no case of port site metastasis was observed during the follow-up period. We routinely avoid systemic injury by meticulous preparation and by removing some Gerota fascia around the specimen.

The reported bladder recurrence rate worldwide is $9-48 \%$ with different methods used for controlling the bladder cuff., ${ }^{2,19}$ In the current series, bladder recurrence rate was (28.6\%). Only one patient developed tumor of the bladder in the region of the ipsilateral ostium (7.1\%). One patient died from distant metastasis. One patient had coincidental Bellini duct renal tumor and developed psoas metastasis (diagnosed with CT guided biopsy) after eight months. He received radiotherapy. Lymphadenectomy was also feasible without any difficulty. None of our patients had presented or developed lymph node disease during follow up. The overall survival as seen in Table 2 is comparable with the current series. A 2-year disease specific survival of $91 \%$ may be also explained by the patient selection and short follow up.

No significant difference in disease specific or overall survival was found between both the retroperitoneoscopic nephrectomy and the open procedure. ${ }^{2,18-20}$ Current data confirm these results and proved the oncological safety of RENU to be comparable with the standard open nephroureterectomy approach.

The major drawbacks of this study are the limited number of patients, the limited followup time and the selected patient population. However, our main intention was to show technical feasibility and proof of adequacy using
Table 1. Pre-operative characteristics of the patients with upper urinary tract transitional cell cancer.

\begin{tabular}{|c|c|c|}
\hline Variable & Patient number & Median/percent \\
\hline Age & 52-92 years & 71.6 \\
\hline $\begin{array}{l}\text { Sex } \\
\quad \text { Male } \\
\text { Female }\end{array}$ & $\begin{array}{l}8 \\
6\end{array}$ & $\begin{array}{l}57.1 \% \\
42.9 \%\end{array}$ \\
\hline $\begin{array}{l}\text { Side } \\
\quad \text { Right } \\
\text { Left }\end{array}$ & $\begin{array}{l}9 \\
5\end{array}$ & $\begin{array}{l}64.3 \% \\
35.7 \%\end{array}$ \\
\hline $\begin{array}{l}\text { Tumor location } \\
\text { Renal pelvis } \\
\text { Ureter } \\
\text { Both } \\
\end{array}$ & $\begin{array}{l}9 \\
3 \\
2\end{array}$ & $\begin{array}{l}64.3 \% \\
21.4 \% \\
14.3 \%\end{array}$ \\
\hline Concomitant or history of bladder cancer & 1 & $7.1 \%$ \\
\hline Positive cytology & 6 & $42.9 \%$ \\
\hline $\begin{array}{l}\text { Pre-operative biopsy } \\
\text { Low grade } \\
\text { High grade } \\
\text { Negative } \\
\end{array}$ & $\begin{array}{l}2 \\
12(1 \text { with CIS }) \\
0\end{array}$ & $\begin{array}{l}14.3 \% \\
85.7 \% \\
0\end{array}$ \\
\hline
\end{tabular}

Table 2. The postoperative pathological findings of the patients with upper urinary tract transitional cell cancer.

\section{Patient number}

\begin{tabular}{ll} 
Pathological stage & \\
Ta & 2 \\
Tis & 2 (one with associated Tla) \\
T1 & 3 (one with associated Tis) \\
T2 & 3 \\
T3 & 4 \\
Grade & \\
Low & 6 \\
High & 8 \\
\hline Node & \\
Negative & 14 \\
Positive & 0 \\
Recurrence & \\
Total & 1 \\
Bladder & 4 \\
Local & 0 \\
\hline Distant metastasis & 1 \\
Follow-up time (months) & $4-36$ \\
Survival rate & \\
2-year & $91 \%$ \\
\hline
\end{tabular}

Table 3. Comparison of the published data about retroperitoneoscopic nephroureterectomy for UT-TCC.

\begin{tabular}{|c|c|c|c|c|c|c|c|c|}
\hline Authors (Year) & $\begin{array}{l}\text { Patient } \\
\text { number }\end{array}$ & $\begin{array}{l}\text { Technique of } \\
\text { bladder cuff } \\
\text { excision }\end{array}$ & $\begin{array}{l}\text { Operating } \\
\text { time (min) }\end{array}$ & $\begin{array}{c}\text { Mean blood } \\
\text { loss (ml) }\end{array}$ & $\begin{array}{l}\text { Compl } \\
\text { minor }\end{array}$ & $\begin{array}{l}\text { cations } \\
\text { 0) } \\
\text { major }\end{array}$ & $\begin{array}{l}\text { Bladder } \\
\text { tumor (\%) }\end{array}$ & $\begin{array}{c}\text { Median } \\
\text { follow- up } \\
\text { time (Mon) }\end{array}$ \\
\hline Chung ${ }^{15} 1996$ & 7 & Open & 275 & $\mathrm{NA}$ & 14 & 0 & NA & NA \\
\hline Gill $^{11} 2000$ & 42 & $\begin{array}{l}\text { Transurethral } \\
\text { detachment }\end{array}$ & 269 & 242 & 7 & 5 & 23 & 11 \\
\hline Uozumil' ${ }^{16} 2002 *$ & 10 & Open & 456 & 462 & 30 & 10 & $\mathrm{NA}$ & NA \\
\hline Matsuil ${ }^{17} 2002^{* *}$ & 17 & Open & 287 & 151 & $\mathrm{NA}$ & NA & NA & 8.8 \\
\hline Goel $^{18} 2002$ & 9 & Open & 189 & NA & 0 & 0 & $\mathrm{NA}$ & 17.7 \\
\hline Kawauchi $^{19} 2003$ & 34 & $\begin{array}{l}\text { Open/transurethral } \\
\text { excision }\end{array}$ & 233 & 236 & 6 & 6 & 9 & NA \\
\hline Yoshino $^{12} 2003$ & 23 & $\begin{array}{l}\text { Extravesical } \\
\text { stabling }\end{array}$ & 330 & 304 & 0 & 0 & 17.3 & 19 \\
\hline Rassweiler² 2004 & 23 & Open & 200 & 450 & 9 & 9 & 34.8 & NA \\
\hline Current series (RENU) & 14 & Open & 154.5 & 134 & 0 & 0 & 28.6 & 23 \\
\hline
\end{tabular}

*Hand assisted technique, ${ }^{* *}$ with patient repositioning, NA, not available 
quality control parameters, such as complication rate, possibility of lymphadenektomie, and postoperative morbidity, and to propose a standardized approach that will hopefully offer a basis for comparative studies in the future.

\section{Conclusions}

The described RENU-technique is a low-risk and minimally invasive procedure and might be an attractive alternative to both laparoscopic as well as open techniques. From the oncological point of view, it is not associated with an increased risk of tumor recurrence; however, long-term follow up is necessary before this can become a standard therapy for UCC of the upper tract.

\section{References}

1. Gonzalez CM, Batler RA, Schoor RA, et al. A novel endoscopic approach towards resection of the distal ureter with surrounding bladder cuff during hand assisted laparoscopic nephroureterectomy. J Urol 2001;165:483.

2. Rassweiler JJ, Schulze M, Marrero R, et al. Laparoscopic nephroureterectomy for upper urinary tract transitional cell carcinoma: is it better than open surgery? Eur Urol 2004;46:690-7.

3. Clayman RV, Kavoussi LR, Figenshau RS, et al. Laparoscopic nephroureterectomy: initial clinical case report. J Laparoendoscopic Surg 1991;1:343-9.

4. El Fettouh HA, Rassweiler JJ, Schulze M, et al. Laparoscopic radical nephroureterectomy: results of an international multicen- ter study. Eur Urol 2002;42:447-52.

5. Rouprêt M, Hupertan V, Sanderson KM, et al. Oncologic control after open or laparoscopic nephroureterectomy for upper urinary tract transitional cell carcinoma: a single centre experience. Urology 2007;69: 656-61.

6. Tsujihata M, Nonomura N, Tsujimura A, et al. Laparoscopic nephroureterectomy for upper tract transitional cell carcinoma: comparison of laparoscopic and open surgery. Eur Urol 2006;49:332-6

7. Hattori R, Yoshino Y, Gotoh M, et al. Laparoscopic nephroureterectomy for transitional cell carcinoma of renal pelvis and ureter: Nagoya experience. Urology 2006;67:701-5.

8. Muntener M, Nielsen ME, Romero FR, et al. Long term oncologic outcome after laparoscopic radical nephroureterectomy for upper tract transitional cell carcinoma. Eur Urol 2007;51:1639-44.

9. Hsueh TY, Huang YH, Chiu AW, et al. Survival analysis in patients with upper urinary tract transitional cell carcinoma: a comparison between open and handassisted laparoscopic nephroureterectomy. BJU Int 2007;99:632-6.

10. Gill IS, Soble JJ, Sung GT, et al. A novel technique for management of the en bloc bladder cuff and distal ureter during laparoscopic nephroureterectomy. J Urol 1999;161:430-4.

11. Gill IS, Sung GT, Hobart MG, et al. Laparoscopic radical nephroureterectomy for upper tract transitional cell carcinoma: the Cleveland Clinic experience. J Urol 2000;164:1513-59.

12. Yoshino Y, Ono Y, Hattori R, et al. Retroperitoneoscopic nephroureterectomy for transitional cell carcinoma of the renal pelvis and ureter: Nagoya experience. Urology 2003;61:533-8.
13. Yoshimura K, Ichioka K, Matsui Y, et al. Alteration of body configuration after retroperitoneoscopic nephrectomy and nephroureterectomy. BJU Int 2005;95: 384-8

14. Saika T, Nishiguchi J, Tsushima T, et al. Comparative study of ureteral stripping versus open ureterectomy for nephroureterectomy in patients with transitional carcinoma of the renal pelvis. Urology 2004;63:848-52.

15. Chung HJ, Chiu AW, Chen KK, et al. Retroperitoneoscopy-assisted nephroureterectomy for the management of upper tract urothelial cancer. Min Inv Ther 1996; 5:266.

16. Uozumi J, Fujiyama C, Meiri $\mathrm{H}$, et al. Hand-assisted retroperitoneoscopic nephroureterectomy for upper urinary-tract urothelial tumours. J Endourol 2002;16: 743-7.

17. Matsui Y, Ohara H, Icihoka K, et al. Retroperitoneoscopy-assisted total nephroureterectomy for upper urinary tract transitional cell carcinoma. Urology 2002; 60:1010-15.

18. Goel A, Hemal AK, Gupta NP. Retroperitoneal laparoscopic radical nephrectomy and nephroureterectomy and comparison with open surgery. World J Urol 2002;20: 219-23.

19. Kawauchi A, Fujiti A, Ukimura 0, et al. Hand-assisted retroperitoneoscopic nephroureterectomy: comparison with the open procedure. J Urol 2003;169:890-4.

20. Taweemonkongsap T, Nualyong $\mathrm{C}$, Amornvesukit T, et al. Outcomes of surgical treatment for upper urinary tract transitional cell carcinoma: Comparison of retroperitoneoscopic and open nephroureterectomy. World J Surg Oncol 2008;6:3. 